\title{
Comparing problem-based learning students to students in a lecture-based curriculum: learning strategies and the relation with self-study time
}

\author{
Marit Wijnen $^{1} \cdot$ Sofie M. M. Loyens ${ }^{2} \cdot$ Guus Smeets $^{3}$ •

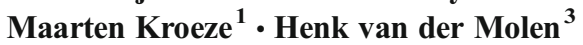

Received: 15 September 2015 /Revised: 24 February 2016 / Accepted: 26 February 2016 / Published online: 16 March 2016

(C) The Author(s) 2016. This article is published with open access at Springerlink.com

\begin{abstract}
In educational theory, deep processing (i.e., connecting different study topics together) and self-regulation (i.e., taking control over one's own learning process) are considered effective learning strategies. These learning strategies can be influenced by the learning environment. Problem-based learning (PBL), a student-centered educational method, is believed to stimulate the use of these effective learning strategies. Several aspects of PBL such as discussions of real-life problems, selecting literature by the students themselves, and formulating answers to learning issues encourage students' use of deep processing and self-regulation. In the present study, third-year PBL law students were compared to third-year law students of a lecture-based program with respect to their learning strategies, which were measured with the Inventory Learning Styles (ILS; Vermunt in British Journal of Educational Psychology, 68, 149-171, 1998). In addition, the relation between time invested in self-study
\end{abstract}

Marit Wijnen

wijnen@law.eur.nl

Sofie M. M. Loyens

s.loyens@ucr.nl

Guus Smeets

smeets@fsw.eur.nl

Maarten Kroeze

kroeze@law.eur.nl

Henk van der Molen

vandermolen@fsw.eur.nl

1 Erasmus School of Law, Erasmus University Rotterdam, Burgemeester Oudlaan 50, 3062 PA Rotterdam, Netherlands

2 University College Roosevelt, Lange Noordstraat 1, 4331 CB Middelburg, Netherlands

3 Department of Psychology, Education \& Child Studies, Faculty of Social Sciences, Erasmus University Rotterdam, Burgemeester Oudlaan 50, 3062 PA Rotterdam, Netherlands 
and learning strategies, when taking the instructional method into account, was explored. Results showed that PBL students reported to apply deep processing, self-regulation, and external regulation more frequently than their non-PBL counterparts. PBL seems to contribute to the use of effective learning strategies, but PBL students also relied more often on external sources for their regulation, such as teachers, course material, and assessment.

Keywords Deep processing $\cdot$ Learning strategies $\cdot$ Problem-based learning $\cdot$ Self-regulation

\section{Introduction}

For students in higher education, self-study is always an important part of the study program. Self-study can be approached in two ways, quantitatively and qualitatively (Doumen et al. 2014). The quality of learning focuses on how students learn. More specifically, the strategies and activities that students apply during self-study give an indication of the quality of their learning. The quantity, on the other hand, can be referred to as time investment. Some students spend more time on studying than others.

Whether the time invested in learning plays an important role in academic success is still a point of debate (e.g., Doumen et al. 2014; Plant et al. 2005). However, there is clear evidence that learning strategies and activities are related to academic performance (Mega et al. 2014; Richardson et al. 2012; Vermunt 2005; Vermunt and Vermetten 2004). In turn, learning strategies might be influenced by the learning environment, because some learning environments intend to encourage high-quality learning (Mattick and Knight 2007; Vermunt 2007). Problem-based learning (PBL), a student-centered educational method, can be considered as a learning environment that aims to stimulate effective learning. The present study will investigate whether PBL indeed stimulates effective learning strategies by comparing a PBL and a lecture-based environment with regard to students' study processes.

\section{Learning strategies}

According to Vermunt (1998), learning strategies can be divided into cognitive processing strategies and regulatory strategies. Processing strategies are thinking strategies that are needed in order to process the material to be learned (Vermunt 1998; Vermunt and Vermetten 2004). For instance, when students relate different study concepts to each other and link course material to their own experiences and real-life situations, they study in an effective way (Newble and Entwistle 1986). These ways of learning lead to deep processing and result in a deep understanding of the study content. Less effective processing strategies are, for example, rehearsing learning material till it is memorized, as this results in only a poor or superficial understanding of the material. Therefore, processing strategies such as rehearsal and memorization are often labeled as surface or stepwise processing strategies (Newble and Entwistle 1986; Vermunt 1998).

Regulatory strategies are strategies students use to regulate or control the processing strategies (Vermunt 1998; Vermunt and Vermetten 2004). These can be divided into selfregulation in which students take control of their own learning process, and external regulation, which indicates that students rely on external sources for their regulation, such as teachers, course material, and assessment. Moreover, students can have limited abilities to control their own learning in combination with limited external regulation, resulting in a third 
form of regulation processes: lack of regulation (Vermunt and Vermetten 2004). Being selfregulated is considered to be more effective than external regulation and lack of regulation, since students with self-regulated learning (SRL) skills are able to set goals, monitor, and motivate themselves to achieve those goals (English and Kitsantas 2013).

Learning strategies of students can be influenced by the applied instructional educational method in the study program (Vermetten et al. 2002; Vermunt 2007). PBL is believed to foster the use of deep processing and self-regulation (Mattick and Knight 2007) and therefore aims to stimulate high-quality learning.

\section{Problem-based learning}

PBL is a student-centered educational method that emphasizes collaboration on realistic problems under guidance of a tutor. The aim of PBL is both to enhance students' intrinsic motivation and their knowledge construction (Barrows 1986; Hmelo-Silver 2004; Loyens et al. 2012; Norman and Schmidt 1992). PBL stresses the importance of an active role of students in their learning process, meaning that students need to construct their own knowledge rather than passively receiving information (Barrows 1996; Hmelo-Silver 2004).

The process of PBL can be divided into the pre-discussion, the self-study phase, and the reporting phase (Schmidt 1983). In the pre-discussion, students start the learning process by working in groups of 10 to 12 on a realistic, ill-defined problem, which usually describes a situation that can occur in real life and elicits discussion in the group. Students receive the problem at the beginning of their learning process, before they have acquired any knowledge about the topic of the problem. They try to come up with explanations and possible solutions, based on their experiences and common sense, and hence they activate their prior knowledge. The advantage of this prior knowledge activation is that new information can be connected to already existing knowledge, which is referred to as the process of elaboration (Schmidt 1983). Elaboration has shown to be beneficial in terms of knowledge retention (e.g., Dochy et al. 2003). Because prior knowledge is limited, several aspects of the discussed problem stay unclear and students collaboratively formulate questions (i.e., learning issues) about the aspects of the problem that need further investigation and explanation. These learning issues guide students during their self-study period in which students individually select and study different literature resources in order to answer the learning issues. After a few days of selfstudy time, students come together for the reporting phase. In this phase, the studied literature is discussed and the learning issues are answered in the group. The tutor, who is present during the pre-discussion and the reporting phase, facilitates the learning process through encouragement of more in-depth thinking about the studied material, for example, by asking students to apply the discussed material to another realistic case (Hmelo-Silver 2004; Loyens et al. 2012; Schmidt 1983).

\section{Problem-based learning's influence on learning strategies}

Several aspects of PBL intend to stimulate students' use of deep processing (e.g., Lycke et al. 2006; Mattick and Knight 2007; Schmidt et al. 1987; Van der Veken et al. 2008). In the prediscussion, students try to explain the given problem, based on their prior knowledge and experiences. During self-study and the reporting phase, students gather new knowledge about the topic of the problem. Deep processing is stimulated when students connect their existing knowledge and experiences to the newly learned knowledge (i.e., elaboration). In addition, 
deep processing and concrete processing are stimulated because information is learned in the context of a realistic situation (i.e., the problem), which facilitates students to connect learned knowledge to practice. Further, in self-study, students should study multiple literature sources and learn from their fellow students in the reporting phase. Therefore, they need to connect different sources and different learning concepts to each other in order to complete and understand the answers on the learning issues discussed during the reporting phase. Moreover, the role of the tutor is to stimulate this by asking in-depth questions. Hence, deep processing strategies, such as making connections between different learning concepts and linking these to practice, are stimulated in the PBL process.

Despite these encouraging components of PBL, studies investigating the effects of PBL on deep processing showed mixed results (Loyens et al. 2013; Dolmans et al. 2015). Some studies demonstrated more deep processing of PBL students and more surface processing by non-PBL students (e.g., Newble and Clarke 1986), while other studies found no effects of PBL on deep learning (e.g., McParland et al. 2004). A recent review of Dolmans et al. (2015) indicates that, in general, PBL seems to positively influence the use of deep processing in students but that mixed results can partly be explained by the environmental characteristics in which the study takes place: A positive effect on deep learning is only present when it is investigated in a curriculum-wide implementation of PBL instead of a one-course implementation (Dolmans et al. 2015).

PBL also intends to stimulate self-regulated learning (English and Kitsantas 2013; Mattick and Knight 2007). Self-regulated learning is often confused with self-directed learning (Loyens et al. 2008), one of the goals of PBL (Barrows 1986; Hmelo-Silver 2004; Loyens et al. 2012; Norman and Schmidt 1992). Self-directed learning is to a certain degree similar to self-regulated learning (e.g., active engagement of students), however not identical. While selfregulation can be seen as a learner characteristic only, self-directed learning is assumed to be both a learner characteristic as well as a learning environment characteristic (Loyens et al. 2008). PBL can be considered a self-directed educational method that stimulates both selfdirected learning and self-regulation in students (for an extended description on self-directed learning and self-regulation, we refer to Loyens et al. 2008). Several elements of PBL, which are outlined below, contribute to the stimulation of self-regulation.

Students in PBL need to select the literature themselves to address the learning issues. This literature search results in a certain degree of freedom to find answers for the learning issues that have been formulated in the group. Further, PBL fosters self-regulated activities, such as monitoring, planning, and self-evaluation. Students need to prepare themselves for every tutorial meeting and therefore monitor and carefully plan their self-study time each week. After the reporting phase, students should evaluate whether the formulated answers to the learning issues in the group were satisfying. If not, they can decide to study additional literature. Moreover, as the tutor only facilitates the process (e.g., asking in-depth questions instead of providing information), students need to take responsibility for their own learning themselves, which stimulates them to be self-regulated (English and Kitsantas 2013).

Previous studies attempted to investigate the influence of PBL on learning strategies. Lycke et al. (2006) compared medical university students of a PBL program to students of a traditional educational program on their regulation strategies. It was shown that PBL students reported more use of self-regulation and made more use of independent resources, such as textbooks. No differences on external regulation were found. In a study of Van der Veken et al. (2008), medical university students of a PBL cohort were also compared to students of a traditional, lecture-based cohort, and it was found that PBL students reported less use of 
surface processing (i.e., memorizing and rehearsal) and more use of self-regulation compared to their non-PBL counterparts. No difference on external regulation was found, in line with Lycke et al. (2006). Galand et al. (2010) compared two cohorts of students in engineering education (i.e., traditional vs. PBL cohort) and also found PBL students to report more use of deep processing, less use of surface processing, and more self-regulated learning (i.e., monitoring and supervision). However, a study by Nijhuis et al. (2005) found that after redesigning an international business studies course in line with PBL characteristics, students used less deep learning and more surface learning, which is contrary to previous findings. In similar vein, mixed findings with regard to PBL effects on processing strategies were discussed before (Dolmans et al. 2015; Loyens et al. 2013).

A possible explanation for these mixed results on learning strategies is the difference in academic disciplines in which these studies took place (i.e., medical education in Lycke et al. 2006; engineering education in Galand et al. 2010; international business education in Nijhuis et al. 2005). This is supported by a study of Dahlgren and Dahlgren (2002) in which it is shown that students in different academic disciplines (i.e., psychology, physiotherapy, and computer engineering) experience their study programs in PBL in different ways. In order to get a clearer image of the impact of PBL on students' learning strategies, it is important to study the role of PBL in different disciplines, so results can be generalized and more clarity on its effects can be obtained (Galand et al. 2010). The present study will therefore focus on PBL and learning strategies among Dutch law students, as to our knowledge, learning strategies in PBL are not studied in law education before. The present study aims to shed light on the role of PBL in fostering effective learning strategies, given the mixed findings of previous studies. Our first research question is as follows: What are the main differences between students in a PBL and a lecture-based program on their learning strategies (i.e., processing and regulatory strategies)?

\section{The relation between self-study time and learning strategies}

Whether time spent on studying alone predicts academic achievement is uncertain, but rather learning strategies matter with regards to understanding and achievement (Doumen et al. 2014; Plant et al. 2005). However, it can be argued that there is a relationship between study time and learning strategies.

Several studies investigated this relationship. It has been demonstrated that university students who apply self-regulation need less study time, because they know how to spend their time more efficiently (Van den Hurk 2006). Further, Kember et al. (1995) indicated that engineering students' use of surface processing was positively correlated with study time. A possible explanation for this finding is that students who use surface processing face difficulties distinguishing between relevant (e.g., underlying principles) and irrelevant (e.g., side issues) information and therefore try to memorize all information, resulting in longer self-study time (Kember et al. 1995). Kember et al. (1995) and Van den Hurk (2006) demonstrated that students need more time when they study in an ineffective way. On the other hand, Wilkinson et al. (2007) showed that medical university students who invested much time in studying also reported more use of deep processing, indicating a positive relationship between time spent on studying and an effective learning strategy (i.e., deep processing). An explanation for this finding is that applying deep processing during study, such as finding connections between different study topics, results in longer study time. In short, studies that investigated the relation between study time and learning strategies show mixed results. 
These contradictions show that the relationship between time spent on study and learning strategies is unclear. It can be, however, that this relation is influenced by another factor, specifically the implemented instructional method. PBL attempts to stimulate students' use of effective learning strategies, such as deep learning and self-regulation (Mattick and Knight 2007), which could influence the relation between time spent on study and applied learning strategies. Moreover, time available for self-study could also differ between instructional methods (Schmidt et al. 2010). When too much contact hours are available in a program, there will be less time available for self-study. Taking the instructional method into account as a moderator variable when investigating the relationship between study time and learning strategies might provide more information on this relation. The second research question is therefore as follows: How are self-study time and learning strategies related to each other, when taking the learning environment (i.e., PBL vs. lecture-based) into account as moderator?

\section{Present study}

The present study focused on the difference in learning strategies between students of a PBL and a lecture-based program. It was hypothesized that PBL students would show more deep processing and self-regulation, because PBL is assumed to stimulate the use of deep processing (e.g., encouraging students to connect different study topics) and self-regulation (e.g., students need to monitor their study time carefully). Moreover, the relation between learning strategies and time spent on study is not clearly defined and yet the current study will explore this relation when taking the educational method into account as moderator variable.

The present study also addresses a different academic discipline. Previous studies focusing on PBL and learning strategies were conducted in medical education (Lycke et al. 2006; Van der Veken et al. 2008), engineering education (Galand et al. 2010), and business education (Nijhuis et al. 2005). PBL appears to have different outcomes in different academic areas (Dahlgren and Dahlgren 2002), which can explain mixed findings concerning PBL effects on learning strategies. Since learning strategies were, to our knowledge, not investigated in law education before, the present study took place in a Dutch law program.

\section{Method}

\section{Learning environment}

The educational program of the School of Law of a Dutch university, in which the current study took place, consists of a 3-year bachelor program and a 1-year master program. At the start of the academic year in September 2012, a PBL curriculum was implemented. Students who enrolled in the School of Law before September 2012 were not taught according the principles of PBL, but in a traditional, lecture-based way. In this lecture-based program, the academic year consisted of four 8-week periods with a total of eight courses. During each period, two courses were offered parallel and, each week, multiple lectures were provided. Some courses offered a weekly workgroup, where a teacher discussed a particular law case. The number of contact hours was approximately $12 \mathrm{~h}$ per week. Four exam weeks took place during the academic year, in which the students were assessed on their knowledge and skills. 
In the new PBL program, a total of eight courses are offered sequentially within one academic year, each lasting 5 weeks and all ending with a written examination. In PBL, the focus lies on tutorial meetings that occur twice a week. In these meetings, the pre-discussion (i.e., collaborative discussion of a realistic problem prior to self-study) and the reporting phase of the previous problem (i.e., discussion of the studied literature) take place and students have sufficient time for self-study in between these meetings. Lectures (i.e., one or two each week) and practical courses are offered next to the tutorial meetings and serve the purpose of extending students' understanding of course material (i.e., lectures) and teaching students how to apply the learned material in real-life law cases (i.e., practical courses). The number of contact hours is approximately $8 \mathrm{~h}$ per week. The current study was conducted within one program, to control for particular variables such as course content and teaching faculty.

\section{Design and participants}

Third-year Dutch law students of a lecture-based program and a PBL program participated in this study. Students of the lecture-based cohort enrolled in their first year of the study program Dutch law in September 2011, a year before the switch to PBL. Students of the PBL cohort registered their first year of Dutch law in September 2012, after the switch. At the time of participating in this study, all students had entered their third year of the bachelor study program.

A total of 338 students participated voluntarily. In the PBL group, 158 third-year Dutch law students $(36 \%$ males) participated. Mean age was 21.54 years $(S D=1.82)$. Participants of the lecture-based group were 180 third-year Dutch law students (38\% males) with a mean age of 22.49 years $(S D=2.60)$. The participants were quite representative for the total number of third-year students. Around $80 \%$ of the lecture-based students and around $70 \%$ of the PBL students in the third year participated.

Students of the lecture-based group were significantly older than students of the PBL group, $t(336)=3.84, p<.001$. This age difference can be explained by a higher number of students in the lecture-based group with a study delay (70\% compared to $30 \%$ of the PBL students), and therefore a higher age. No differences in gender between both groups were present, $\chi^{2}(1)=.16, p=.689$. The gender distribution (i.e., percentage male and female) in both groups is common for law study programs in higher education in the Netherlands (Central Bureau for Statistics 2014).

\section{Material}

Learning strategies The first part of the Inventory Learning Styles (ILS; Vermunt 1998) was used to measure students' learning strategies (i.e., processing strategies and regulatory strategies). The ILS is a self-report questionnaire in which students rate statements on a scale of 1 ("I never or hardly do this") to 5 ("I (almost) always do this"). Items regarding processing strategies are distinguished in (a) deep processing, which focus on relating topics, structuring, and critical processing, (b) stepwise processing, in which the use of memorization, rehearsal, and analyzing is measured, and (c) concrete processing, which measures whether learning material is concretized and personalized by the student. Further, items on regulatory processes are divided into (d) self-regulation, which measures to what degree students control their own learning process, (e) external regulation, which measures to what degree students 
depend on external resources (e.g., a teacher) for steering and controlling their learning process, and (f) lack of regulation, which measures the inability of students to regulate the learning process. In total, the questionnaire contained 55 items. Table 1 provides an overview of the subscales with example items of the ILS and Cronbach's alphas for each subscale. The Cronbach's alphas can be considered acceptable, with the exception of the scale "external regulation" $(\alpha=.64)$, which has a rather low reliability. Results on the scale external regulation should therefore be interpreted with caution.

Self-study time Students were asked to give an estimation of their weekly time investment on self-study (in hours) prior to the ILS, by asking the question, "How many hours, on average, do you spend each week on self-study?" Previous research has showed that there is a strong connection between self-reported study time and actual time spent on study in PBL (Moust 1993).

\section{Procedure}

In both groups, the teacher (i.e., in the lecture-based cohort) or tutor (i.e., in the PBL cohort) handed out the questionnaire on paper to students during a regular study week and students took about 15 min to fill it out. Students of the lecture-based cohort participated in the current study during the given course of the third academic year in January 2014. The course at the time was called "moot court," in which students learn to plea in front of a judge. Students of the PBL cohort participated in the current study exactly 1 year later, in January 2015, when they were in their third academic year. Students of this cohort were enrolled in the course "criminal law" at the time of the study. All students were instructed to report on their learning strategies and self-study time in general, not in the specific course given at the time.

Table 1 Example items and Cronbach's alphas of each subscale of the learning strategies in the ILS

\begin{tabular}{|c|c|c|c|}
\hline $\begin{array}{l}\text { Learning } \\
\text { strategy }\end{array}$ & Subscale & Example item & $\begin{array}{l}\text { Cronbach's } \\
\text { alpha }\end{array}$ \\
\hline \multirow[t]{3}{*}{ Processing } & $\begin{array}{l}\text { Deep processing } \\
\quad(n=11)\end{array}$ & "I try to combine separately discussed concepts to a whole" & .82 \\
\hline & $\begin{array}{l}\text { Stepwise } \\
\text { processing } \\
(n=11)\end{array}$ & $\begin{array}{l}\text { "I rehearse important topics of the learning material till I } \\
\text { memorize them" }\end{array}$ & .79 \\
\hline & $\begin{array}{l}\text { Concrete } \\
\text { processing } \\
(n=5)\end{array}$ & $\begin{array}{l}\text { "I use what I learn on a course in my activities outside the } \\
\text { study" }\end{array}$ & .72 \\
\hline \multirow[t]{3}{*}{ Regulation } & $\begin{array}{l}\text { Self-regulation } \\
\quad(n=11)\end{array}$ & $\begin{array}{l}\text { "When I'm having difficulties with parts of the course } \\
\text { material, I try to analyze why it is hard for me" }\end{array}$ & .80 \\
\hline & $\begin{array}{l}\text { External } \\
\quad \text { regulation } \\
\quad(n=11)\end{array}$ & $\begin{array}{l}\text { "I study according to the instructions provided by course } \\
\text { materials or the teacher" }\end{array}$ & .64 \\
\hline & $\begin{array}{l}\text { Lack of } \\
\text { regulation } \\
(n=6)\end{array}$ & $\begin{array}{l}\text { "I confirm that I find it difficult to determine whether or not I } \\
\text { sufficiently mastered the course material" }\end{array}$ & .75 \\
\hline
\end{tabular}




\section{Statistical analyses}

In order to compare students of both learning environments on their learning strategies, a multivariate analysis of variance (MANOVA) was conducted with educational method as between-subjects factor (i.e., PBL vs. lecture-based) and scores on the three subscales of processing strategies (i.e., deep, surface, and concrete processing) and the three regulatory strategies (i.e., self, external, and lack of regulation) as dependent variables. In order to study the influence of the learning environment on the relation between learning strategies and selfstudy time, moderation analyses were conducted with PROCESS (Hayes 2012). Self-study time and educational method (i.e., PBL group vs. lecture-based group) served as predictors, and scores on the ILS subscales as outcome variables. Instructional method was considered a moderator variable, and a moderation effect was present when an interaction effect between self-study time and instructional method appeared for the different subscales (Field 2013). When an interaction effect is present, the relation between self-study time and the scores on learning strategies is different in both learning environments, indicating a moderator effect.

\section{Results}

\section{Differences between PBL students and students of a lecture-based environment on learning strategies}

Prior to the analyses, two univariate outliers were excluded (i.e., values $2.58 S D$ above the mean), resulting in a total number of 336 participants. Mean item scores on the processing and regulation strategies and self-study time for participants of both groups are given in Table 2. At first sight, scores between the two groups did not seem to differ much. Self-study time did not differ between both groups $t(323)=.90, p=.371$. Further, the PBL students seem to report a higher score on deep processing, stepwise processing, self-regulation, and external regulation. In order to say more about these differences and hence answer our first research question, a MANOVA with follow-up ANOVAs was conducted.

The MANOVA showed a significant effect of instructional method, Pillai's trace $V=.06$, $F(6,329)=3.27, p=.005, \eta_{\mathrm{p}}{ }^{2}=.06$. Separate univariate ANOVAs on the ILS subscales were

Table 2 Mean item scores on all subscales of the ILS and self-study time for both groups ( $S D$ in parentheses)

\begin{tabular}{llll}
\hline & & \multicolumn{1}{l}{ Condition } & \\
\cline { 3 - 4 } & & PBL & Lecture-based \\
\hline Processing strategies & Deep processing & $3.03(.59)$ & $2.89(.67)$ \\
& Stepwise processing & $3.03(.60)$ & $2.90(.62)$ \\
Regulation strategies & Concrete processing & $2.91(.71)$ & $2.93(.74)$ \\
& Self-regulation & $2.62(.60)$ & $2.43(.66)$ \\
Self-study time & External regulation & $3.23(.49)$ & $3.08(.50)$ \\
& Lack of regulation & $2.36(.73)$ & $2.45(.77)$ \\
& & $11.99(6.09)$ & $12.68(7.44)$ \\
\hline
\end{tabular}

Scores on all subscales could range from 1 to 5 . Self-study time score is displayed in hours. The range of the reported number of self-study hours per week varied between 0 and 50 
conducted. Effect sizes were expressed in eta squared (i.e., $\eta^{2}$ ). Effect sizes of $.01, .06$, and .14 indicate small, mediate, and large effect, respectively. The ANOVAs showed that students in the PBL group more frequently applied deep processing, $F(1,334)=4.15, p=.042, \eta^{2}=.01$, self-regulation, $F(1,334)=7.41, p=.007, \eta^{2}=.02$, and external regulation, $F(1,334)=7.39$, $p=.007, \eta^{2}=.02$, compared to students in the lecture-based group. No differences between groups were found on stepwise processing, concrete processing, and lack of regulation, respectively, $F(1,334)=1.42, p=.054, \eta^{2}=.01 ; F(1,334)=.27, p=.820, \eta^{2}=.00$; and $F(1$, $334)=.64, p=.285, \eta^{2}=.00$.

\section{Influence of the learning environment on the relation between learning strategies and self-study time}

Self-study time appeared positively skewed (skewness $=1.27, S E=.14$, kurtosis $=2.72$, $S E=.27$ ), and therefore a square root transformation on the self-study time data was performed. This transformation resolved the issues of skewness and kurtosis (skewness $=.24$, $S E=.14$, kurtosis $=.51, S E=.27$ ). As a result of missing values on self-study time, the total number of participants in these analyses became 327. Table 3 gives a correlation matrix with correlations between all subscales of the ILS and transformed self-study time. The correlations remarkably show that almost all subscales were positively and significantly related to each other and to study time. Deep processing, concrete processing, and self-regulation were highly correlated to each other, as well as stepwise processing and external regulation.

In order to answer the second research question, moderation analyses were performed. PROCESS (Hayes 2012) was used for the moderation analyses, with instructional type (i.e., PBL vs. lecture-based) as moderator, self-study time as predictor, and the mean scores on the subscales of the ILS as dependent variables. Table 4 presents the results of the moderation analyses. For all subscales of the ILS, the main effect of instructional type, the main effect of self-study time, and the interaction between instructional type and self-study (i.e., moderation effect) are given. Self-study time appeared to be a significant predictor for scores on all subscales. There was a positive relation between self-study time and all types of processing strategies and regulatory strategies (Table 4).

A moderation effect was present when an interaction effect between self-study time and instructional method appeared. With regard to the processing strategies, no interaction effects between the transformed self-study data and instructional methods showed up for any of the

Table 3 Pearson correlations between subscales of the Inventory Learning Styles (ILS) and transformed selfstudy time

\begin{tabular}{|c|c|c|c|c|c|c|}
\hline & 1 & 2 & 3 & 4 & 5 & 6 \\
\hline \multicolumn{7}{|l|}{ 1. Deep processing } \\
\hline 2. Stepwise processing & $.27 *$ & & & & & \\
\hline 3. Concrete processing & $.59 *$ & $.23 *$ & & & & \\
\hline 4. Self-regulation & $.70 *$ & $.44^{*}$ & $.56^{*}$ & & & \\
\hline 5. External regulation & $.30 *$ & $.50 *$ & $.20 *$ & $.35^{*}$ & & \\
\hline 6. Lack of regulation & .07 & $.27 *$ & $.27 *$ & $.27 *$ & $.16^{*}$ & \\
\hline 7. Self-study time & $.19 *$ & $.24 *$ & $.19^{*}$ & $.26^{*}$ & $.19^{*}$ & $.62 *$ \\
\hline
\end{tabular}

$* p<.001$ 
Table 4 Multiple regression analyses with self-study time, instructional type, and their interaction (i.e., moderation effect) for all subscales of the Inventory Learning Styles (ILS)

\begin{tabular}{|c|c|c|c|}
\hline Learning strategy & Effect & $b(\mathrm{SE})$ & $t$ \\
\hline \multirow[t]{3}{*}{ Deep processing } & Self-study time & $.11(.03)$ & $3.29 *$ \\
\hline & Instructional type & $.13(.07)$ & 1.88 \\
\hline & Self-study time $\times$ instructional type & $-.06(.07)$ & -.99 \\
\hline \multirow[t]{3}{*}{ Stepwise processing } & Self-study time & $.14(.07)$ & $3.95^{* *}$ \\
\hline & Instructional type & $.14(.07)$ & $2.10 *$ \\
\hline & Self-study time $\times$ instructional type & $-.01(.07)$ & -.18 \\
\hline \multirow[t]{3}{*}{ Concrete processing } & Self-study time & $.13(.04)$ & $2.93 *$ \\
\hline & Instructional type & $-.02(.08)$ & -.26 \\
\hline & Self-study time $\times$ instructional type & $-.07(.09)$ & -.76 \\
\hline \multirow[t]{3}{*}{ Self-regulation } & Self-study time & $.16(.04)$ & $4.51 * *$ \\
\hline & Instructional type & $.20(.07)$ & $2.88 *$ \\
\hline & Self-study time $\times$ instructional type & $-.04(.07)$ & -.55 \\
\hline \multirow[t]{3}{*}{ External regulation } & Self-study time & $.01(.03)$ & $3.39 * *$ \\
\hline & Instructional type & $.15(.05)$ & $2.75^{*}$ \\
\hline & Self-study time $\times$ instructional type & $.13(.06)$ & $2.19 *$ \\
\hline \multirow[t]{3}{*}{ Lack of regulation } & Self-study time & $.12(.05)$ & $2.58 *$ \\
\hline & Instructional type & $-.07(.08)$ & -.88 \\
\hline & Self-study time $\times$ instructional type & $-.01(.09)$ & -.06 \\
\hline
\end{tabular}

$R^{2}$ deep processing $=.05 ; R^{2}$ stepwise processing $=.07 ; R^{2}$ concrete processing $=.04 ; R^{2}$ self-regulation $=.09$; $R^{2}$ external regulation $=.07 ; R^{2}$ lack of regulation $=.03$

$* p<.05 ; * * p<.001$

processing strategies - deep processing $(t(323)=-1.00, p=.319)$, surface processing $(t(323)=-.18, p=.860)$, and concrete processing $(t(323)=-.76, p=.448)$-indicating that instructional method cannot be considered a moderation variable in the relation between self-study time and the processing strategies. For the regulatory strategies, no interaction effects appeared for self-regulation and lack of regulation, respectively, $t(323)=-.55$, $p=.583 ; t(323)=.06, p=.954$. However, an interaction effect between the transformed selfstudy time data and instructional method was found for external regulation strategies, $t(323)=2.19, p=.030$, demonstrating that instructional method moderates the relationship between time spent on self-study and external regulation. To follow up this interaction, simple slopes were investigated, showing that the relation between self-study time and external regulation is positive for PBL students $(b=.17, S E(b)=.04, t=4.15, p<.001)$, but this relation is non-existing for students in the lecture-based group $(b=.04, S E(b)=.04, t=.89, p=.373)$.

\section{Discussion}

The current study investigated the differences between students of PBL, a learning environment that aims to stimulate deep processing and self-regulation, and students of a lecture-based program on their study strategies. Dutch law students of a PBL group were compared to students of a lecturebased group on their self-reported use of processing (i.e., deep, stepwise, and concrete processing) 
and regulatory strategies (i.e., self-regulation, external regulation, and lack of regulation). It was hypothesized that PBL students would report more use of deep processing and self-regulation. In line with these expectations, PBL students reported more deep processing and self-regulation. In addition, more external regulation was reported by PBL students.

\section{PBL and learning strategies}

With regard to the processing strategies, PBL students reported more frequent use of deep processing compared to their non-PBL counterparts. An explanation lies in specific characteristics of PBL, which aim to foster deep learning (e.g., Mattick and Knight 2007; Schmidt et al. 1987). In a PBL curriculum, students collaboratively discuss a problem, formulate learning issues about the problem, select literature by themselves, and discuss their findings while addressing the learning issues in the reporting phase under guidance of a tutor. PBL students are required to relate different study topics in order to formulate a complete and coherent answer to the learning issues. Moreover, tutors ask students in-depth questions during the pre-discussion and the reporting phase, making that students elaborate more on the material. While previous studies indicated mixed results on the influence of PBL on deep learning (e.g., Loyens et al. 2013), this study found a beneficial outcome of PBL on deep processing. This finding is furthermore in line with outcomes of the review of Dolmans et al. (2015), indicating that PBL positively effects the use of deep processing, especially when it is investigated in a curriculum-wide PBL implementation, as is the case in the present study.

No difference between students of the PBL and the lecture-based cohort was found with respect to reported stepwise processing, which is inconsistent with findings of Galand et al. (2010) and Van der Veken et al. (2008). Yet, considering the mean scores on stepwise processing, PBL students seem to report higher use of stepwise processing compared to the students in the lecture program (respectively, $M=3.03$ and $M=2.90$ ). Although not statistically significant in this study, these results are in line with findings of Nijhuis et al. (2005) and Struyven et al. (2006), which showed higher scores of PBL students on surface learning. Several explanations for this finding can be put forward.

First, the exams used in both curricula could offer an explanation (Baeten et al. 2010; Vermunt 2005). Considering the frequent use of stepwise processing in both cohorts, it might be that exams used in the curricula under study did not always require deep processing in order to receive a sufficient grade, but could (at least partly) be managed with stepwise processing strategies. This explanation is supported by findings of Vermunt (2005), in which a relation was demonstrated between the reported use of stepwise processing in (non-PBL) law students and succeeding exams. Further, the use of deep and surface learning differs between disciplines of study (Baeten et al. 2010; Vermunt 2005), which can explain differences with previous studies. In a study by Vermunt (2005), law students reported more use of rehearsal and memorization techniques (i.e., stepwise processing) compared to students of other disciplines (e.g., psychology and art students).

A final explanation is that a comparison was made between a final cohort of students in a lecture-based, traditional cohort and a first PBL cohort. Problems regarding implementation are likely to arise in a first cohort, as everything is new to both students and academic staff. These problems could possibly influence the found results. The transition to PBL is a major change for the faculty and staff, and this comes with difficulty, such as teachers experiencing trouble switching from a leading role to a guiding role (Stinson and Milter 1996). Moreover, poor implementation can lead to suboptimal tutorial meetings and tutor behavior (Dolmans 
et al. 2005). Issues in the PBL cohort could be an explanation for the lack of differences in stepwise processing and even a higher reported use for PBL students. If, for example, tutors act insufficiently (i.e., too directive or too passive), this can have an influence on students' learning strategies.

With regard to regulatory strategies, the present study showed that PBL students reported more self-regulation. This finding can be explained by elements of PBL that encourage selfregulation in students, such as selection of literature by themselves, stimulation of students to plan their self-study time carefully because of required preparation for every tutorial meeting, and self-evaluation of formulated answers on the learning issues after the reporting phase (English and Kitsantas 2013; Mattick and Knight 2007).

Results further indicated that PBL students were more externally regulated compared to students of the lecture-based group, which means that for regulation of the processing strategies, PBL students depend more often on external sources such as the tutor, teacher, course material, and assessments. This finding contradicts to findings of earlier studies (i.e., Lycke et al. 2006; Van der Veken et al. 2008) in which no effect of PBL on external regulation was found. However, high amounts of external regulation are not that surprising in a PBL curriculum. There are several external factors that could influence students, such as comments of the tutor, fellow students in the tutorial group, and the required preparation every tutorial meeting. The fact that the present study was conducted in a first cohort after implementation (e.g., Dolmans et al. 2005; Stinson and Milter 1996) could also apply for findings on external regulation. For example, when tutors are new to PBL, they might provide too directive guiding, making students depend too much on them. It should, however, be noted that the reliability of the subscale "external regulation" turned out rather low $(\alpha=.64)$, and findings on this subscale should therefore be interpreted with caution.

In sum, results showed positive associations between PBL and deep processing, selfregulation, and external regulation. Results were statistically significant, but all had small effect sizes (respectively, $\eta^{2}=.01, \eta^{2}=.02, \eta^{2}=.02$ ). These effect sizes can be explained by previous studies, highlighting that students' applied learning strategies depend on both the environment as on the individual. This means that learning strategies are vulnerable to change but are also stable to a certain degree (Richardson 2011; Vermunt and Vermetten 2004; Vermetten et al. 1999), which will result in only a small impact, as is the case in the present study. The effect sizes indicate that in practice, PBL students will be quite similar in their applied learning strategies to their non-PBL counterparts. However, the present study also demonstrated that PBL influences students' learning strategies.

\section{PBL effects on the relation between self-study time and learning strategies}

Findings on how the relationship between time investment and learning strategies is defined were inconclusive (e.g., Kember et al. 1995; Wilkinson et al. 2007). Therefore, the current study investigated the relationships between time spent on self-study and the different types of processing and regulatory strategies, with instructional method (i.e., PBL vs. lecture-based) as moderator variable.

Results of the moderation analyses showed a positive relationship between self-study time and all scales of the ILS, meaning that an increase in self-study time is related to an increase in any kind of learning strategy (regardless of the applied instructional method). This finding was surprising, since a distinction between effective and ineffective learners seemed logical and was demonstrated in earlier studies (Kember et al. 1995; Wilkinson et al. 2007). After taking 
the instructional method into account as a moderator variable, results showed only a moderator effect on the scale external regulation, which indicated that an increase in external regulation goes together with an increase in self-study time for PBL students, but this relation is nonexisting for students in the lecture-based cohort. Apparently, when PBL students consider directions from external sources (e.g., teacher and course material), they spend more time on studying. This result is in line with the study of Kember et al. (1995), which indicated a positive relation between self-study time and surface learning. Surface learning and external regulation are both considered undesirable learning outcomes, and this study showed a positive relationship between time invested in study and undesirable learning strategies for PBL students. However, as mentioned before, the reliability of this scale turned out rather low, and these findings should therefore be interpreted with caution. In general, one could argue that the relationship between study time and learning strategies is stable in different learning settings.

\section{Limitations and recommendations for future research}

As with any study, the present study has some limitations. The present study made use of the ILS, a self-reported questionnaire, in order to measure processing and regulatory strategies. This can be considered a limitation on the one hand, because actual learning behavior is not measured. Nevertheless, self-reports for investigating learning activities are probably the most accurate way to measure, because these activities are mostly internal processes. Further, the method of how self-study time was measured yields some disadvantages and might offer an explanation for the findings of the moderation analyses. Students were asked to give an overall estimation of their time investment in self-study, which was applied to the study program in general. This time estimation was very broad. Future research could perhaps obtain time investment on multiple occasions for a more accurate result. Still, it was assumed that thirdyear students were able to provide an accurate estimation of their time investment, because they had 3 years of experience with studying and planning self-study at the time the current study took place.

Further, students of the two cohorts under study were not pre-tested on their learning strategies when they entered university. Hence, it is still somewhat uncertain whether the found differences can be ascribed to the difference in learning environment, because it is unsure whether the student groups differed on how they learned beforehand. However, we have no reason to believe that both student cohorts were significantly different in this respect. A final limitation is that students' perceptions on the learning environment were not taken into account. Previous studies indicate the importance of perceptions of the learning environment on students' use of learning strategies (Baeten et al. 2010; Galand et al. 2010; Struyven et al. 2006). At this point, it is unclear whether students' perceptions of the environment are in line with the principles of PBL (i.e., student-centered). Further research is recommended to take students' perceptions into consideration when investigating the influence of learning environment on students learning strategies.

\section{Conclusions}

The present study compared students of a PBL and a lecture-based curriculum on their selfreported learning strategies in Dutch law. Results showed that the use of deep processing and self-regulation, which are fostered in PBL, are more frequently reported by PBL students. 
Students selecting literature themselves, formulating coherent and complete answers to learning issues, and self-evaluating these answers are beneficial aspects in PBL for applying effective learning strategies. External regulation is also reported more frequently by PBL students compared to their non-PBL counterparts, which indicates that, besides self-regulation, students rely on external factors in PBL (e.g., tutor and fellow students). This study was conducted in Dutch law education, as to our knowledge, learning strategies in PBL were not investigated with law students before. In order to generalize results and get a clearer image on PBL effects, PBL influences on learning strategies should be investigated in different academic areas. The current study contributed to this by focusing on law education.

Open Access This article is distributed under the terms of the Creative Commons Attribution 4.0 International License (http://creativecommons.org/licenses/by/4.0/), which permits unrestricted use, distribution, and reproduction in any medium, provided you give appropriate credit to the original author(s) and the source, provide a link to the Creative Commons license, and indicate if changes were made.

\section{References}

Baeten, M., Kyndt, E., Struyven, K., \& Dochy, F. (2010). Using student-centered learning environments to stimulate deep approaches to learning: factors encouraging or discouraging their effectiveness. Educational Research Review, 5, 243-260. doi:10.1016/j.edurev.2010.06.001.

Barrows, H. S. (1986). A taxonomy of problem-based learning methods. Medical Education, 20, 481-486. doi: 10.1111/j.1365-2923.1986.tb01386.x.

Barrows, H. S. (1996). Problem-based learning in medicine and beyond: a brief overview. In W. H. Gijselaers (Ed.), New directions for teaching and learning (pp. 3-12). San Francisco: Jossey-Bass. doi:10.1002/tl. 37219966804

Central Bureau for Statistics. (2014). Hoger onderwijs; ingeschrevenen, studierichting, herkomstgroepering [Higher Education; registered, disciplines, origin grouping]. Retrieved from CBS StatLine: http://statline. cbs.n1/StatWeb/publication/?VW=T\&DM=SLNL\&PA=71037ned\&LA=NL.

Dahlgren, M. A., \& Dahlgren, L. O. (2002). Portraits of PBL: students' experiences of the characteristics of problem-based learning in physiotherapy, computer engineering and psychology. Instructional Science, 30, 111-127. doi:10.1023/A:1014819418051.

Dochy, F., Segers, M., Van den Bossche, P., \& Gijbels, D. (2003). Effects of problem-based learning: a metaanalysis. Learning and Instruction, 13, 533-568. doi:10.1016/S0959-4752(02)00025-7.

Dolmans, D. H. J. M., De Grave, W., Wolfhagen, I. H. A. P., \& Van der Vleuten, C. P. M. (2005). Problem-based learning: future challenges for educational practice and research. Medical Education, 39, 732-741. doi:10. 1111/j.1365-2929.2005.02205.x.

Dolmans, D. H. J. M., Loyens, S. M. M., Marcq, H., \& Gijbels, D. (2015). Deep and surface learning in problem-based learning: a review of the literature. Advances in Health Sciences Education. doi:10.1007/s10459-015-9645-6.

Doumen, S., Broeckmans, J., \& Masui, C. (2014). The role of self-study time in freshmen's achievement. Educational Psychology: An International Journal of Experimental Educational Psychology, 34, 385-402. doi:10.1080/01443410.2013.785063.

English, M. C., \& Kitsantas, A. (2013). Supporting student self-regulated learning in problem- and project-based learning. Interdisciplinary Journal of Problem-based Learning, 7, 128-150.

Field, A. (2013). Discovering statistics using IBM SPSS statistics: and sex and drugs and rock " $n$ " roll. London: Sage Publications.

Galand, B., Raucent, B., \& Frenay, M. (2010). Engineering students' self-regulation, study strategies, and motivational believes in traditional and problem-based curricula. International Journal of Engineering Education, 26, 523-534.

Hayes, A. F. (2012). A versatile computational tool for observed variable mediation, moderation, and conditional process modeling [White paper]. Retrieved from http:/www.afhayes.com/public/process2012.pdf.

Hmelo-Silver, C. E. (2004). Problem-based learning: what and how do students learn? Educational Psychology Review, 16, 235-266. doi:10.1023/B:EDPR.0000034022.16470.f3.

Kember, D., Jamieson, Q. W., Pomfret, M., \& Wong, E. T. T. (1995). Learning approaches, study time and academic performance. Higher Education, 29, 329-342. doi:10.1007/BF01384497. 
Loyens, S. M. M., Magda, J., \& Rikers, R. M. J. P. (2008). Self-directed learning in problem-based learning and its relationship with self-regulated learning. Educational Psychology Review, 20, 411-427. doi:10.1007/ s10648-008-9082-7.

Loyens, S. M. M., Kirschner, P. A., \& Paas, F. (2012). Problem-based learning. In K. R. Harris, S. Graham, \& T. Urdan (Eds.), APA educational psychology handbook (pp. 403-425). Washington, DC: American Psychological Association. doi:10.1037/13275-016.

Loyens, S. M. M., Gijbels, D., Coertjens, L., \& Côté, D. J. (2013). Students' approaches to learning in problembased learning: taking into account students' behavior in the tutorial groups, self-study time, and different assessment aspects. Studies in Educational Evaluation, 39, 23-32. doi:10.1016/j.stueduc.2012.10.004.

Lycke, H. K., Grøttum, P., \& Strømsø, H. I. (2006). Student learning strategies, mental models and learning outcomes in problem-based and traditional curricula in medicine. Medical Teacher, 28, 717-722. doi:10. $1080 / 01421590601105645$.

Mattick, K., \& Knight, L. (2007). High-quality learning: harder to achieve than we think? Medical Education, 41, 638-644. doi:10.1111/j.1365-2923.2007.02783.x.

McParland, M., Noble, L. M., \& Livingston, G. (2004). The effectiveness of problem-based learning compared to traditional teaching in undergraduate psychiatry. Medical Education, 38, 859-867. doi:10.1046/j.13652929.2004.01818.x.

Mega, C., Ronconi, L., \& De Beni, R. (2014). What makes a good student? How emotions, self-regulated learning, and motivation contribute to academic achievement. Journal of Educational Psychology, 106, 121131. doi: $10.1037 / \mathrm{a} 0033546$.

Moust, J. (1993). De rol van tutoren in probleemgestuurd onderwijs: contrasten tussen student- en docenttutoren [The role of tutors in problem-based learning: contrasts between undergraduate teaching assistants and faculty] (Unpublished doctoral dissertation). University of Maastricht, Maastricht, the Netherlands.

Newble, D. I., \& Clarke, R. M. (1986). The approaches to learning of students in a traditional and in an innovative problem-based medical school. Medical Education, 20, 267-271. doi:10.1111/j.1365-2923.1986. tb01365.x.

Newble, D. I., \& Entwistle, N. J. (1986). Learning styles and approaches: implications for medical education. Medical Education, 20, 162-175. doi:10.1111/j.1365-2923.1986.tb01163.x.

Nijhuis, J. F. H., Segers, M. S. R., \& Gijselaers, W. H. (2005). Influence of redesigning a learning environment on student perceptions and learning strategies. Learning Environments Research, 8, 67-93. doi:10.1007/ s10984-005-7950-3.

Norman, G. R., \& Schmidt, H. G. (1992). The psychological basis of problem-based learning: a review of the evidence. Academic Medicine, 67, 557-565. doi:10.1097/00001888-199209000-00002.

Plant, E. A., Ericsson, K. A., Hill, L., \& Asberg, K. (2005). Why study time does not predict grade point average across college students: implications of deliberate practice for academic performance. Contemporary Educational Psychology, 30, 96-116. doi:10.1016/j.cedpsych.2004.06.001.

Richardson, J. T. E. (2011). Approaches to studying, conceptions of learning and learning styles in higher education. Learning and Individual Differences, 21, 288-293. doi:10.1016/j.indif.2010.11.015.

Richardson, M., Abraham, C., \& Bond, R. (2012). Psychological correlated of university students' academic performance: a systematic review and meta-analysis. Psychological Bulletin, 138, 353-387. doi:10.1037/ a0026838.

Schmidt, H. G. (1983). Problem-based learning: rationale and description. Medical Education, 17, 11-16. doi:10. 1111/j.1365-2923.1983.tb01086.x.

Schmidt, H. G., Dauphinee, W. D., \& Patel, V. L. (1987). Comparing the effects of problem-based and conventional curricula in an international sample. Journal of Medical Education, 62, 305-315.

Schmidt, H. G., Cohen-Schotanus, J., Van der Molen, H. T., Splinter, T. A. W., Bulte, J., Holdrinet, R., \& Van Rossum, H. J. M. (2010). Learning more by being taught less: a "time-for-self-study" theory explaining curricular effects on graduation rate and study duration. Higher Education, 60, 287-300. doi:10.1007/ s10734-009-9300-3.

Stinson, J. E., \& Milter, R. G. (1996). Problem-based learning in business education: curriculum design and implementation issues. New Direction for Teaching and Learning, 68, 33-42. doi:10.1002/tl.37219966807.

Struyven, K., Dochy, F., Janssens, S., \& Gielen, S. (2006). On the dynamics of students' approaches to learning: the effects of the teaching/learning environment. Learning and Instruction, 16, 279-294. doi:10.1016/j. learninstruc.2006.07.001.

Van den Hurk, M. (2006). The relation between self-regulated strategies and individual study time, prepared participation and achievement in a problem-based curriculum. Active Learning in Higher Education, 7, 155169. doi:10.1177/1469787406064752.

Van der Veken, J., Valcke, M., Muijtjens, A., de Measeneer, J., \& Derese, A. (2008). The potential of the inventory of learning styles to study students' learning patterns in three types of medical curricula. Medical Teacher, 30, 863-869. doi:10.1080/01421590802141167. 
Vermetten, Y. J., Vermunt, J. D., \& Lodewijks, H. G. (1999). A longitudinal perspective on learning strategies in higher education - different view-points towards development. British Journal of Educational Psychology, 69, 221-242. doi:10.1348/000709999157699.

Vermetten, Y. J., Vermunt, J. D., \& Lodewijks, H. G. (2002). Powerful learning environments? How university students differ in their response to instructional measures. Learning and Instruction, 12, 263-284. doi:10. 1016/S0959-4752(01)00013-5.

Vermunt, J. D. (1998). The regulation of constructive learning processes. British Journal of Educational Psychology, 68, 149-171. doi:10.1111/j.2044-8279.1998.tb01281.x.

Vermunt, J. D. (2005). Relations between student learning patterns and personal and contextual factors and academic performance. Higher Education, 49, 205-234. doi:10.1007/s10734-004-6664-2.

Vermunt, J. D. (2007). The power of teaching-learning environments to influence student learning. British Journal of Educational Psychology Monograph Series II, 4, 73-90. doi:10.1348/000709906X162406.

Vermunt, J. D., \& Vermetten, Y. J. (2004). Patterns in students learning: relationships between learning strategies, conceptions of learning, and learning orientations. Educational Psychology Review, 16, 359-384. doi: 10. 1007/s10648-004-0005-y.

Wilkinson, T. J., Wells, J. E., \& Bushnell, J. A. (2007). Medical student characteristics associated with time in study: is spending more time always a good thing? Medical Teacher, 29, 106-110. doi: 10.1080/ 01421590601175317.

Current Themes of Research:

Effectiveness of Problem-based Learning (PBL) in legal education

Relevant publication:

Wijnen, M, Loyens, S. M. M., \& Schaap, L. (2015). Experimental evidence of the relative effectiveness of problem-based learning for knowledge acquisition and retention. Interactive Learning Environments. doi:10. 1080/10494820.2015.1060504. 